\title{
Incorporating resident research into the dermatology residency program
}

This article was published in the following Dove Press journal:

Advances in Medical Education and Practice

22 April 2013

Number of times this article has been viewed

\section{Richard F Wagner Jr \\ Sharon S Raimer \\ Brent C Kelly}

Department of Dermatology, The University of Texas Medical Branch,

Galveston, Texas, USA
Correspondence: Richard F Wagner Jr 30I University Blvd, Galveston,

Texas 77555-0738, USA

$\mathrm{Tel}+\mathrm{I} 409772$ I9II

Fax + I 409772 I943

Email rfwagner@utmb.edu
Abstract: Programmatic changes for the dermatology residency program at The University of Texas Medical Branch were first introduced in 2005, with the faculty goal incorporating formal dermatology research projects into the 3-year postgraduate training period. This curriculum initially developed as a recommendation for voluntary scholarly project activity by residents, but it evolved into a program requirement for all residents in 2009. Departmental support for this activity includes assignment of a faculty mentor with similar interest about the research topic, financial support from the department for needed supplies, materials, and statistical consultation with the Office of Biostatistics for study design and data analysis, a 2-week elective that provides protected time from clinical activities for the purpose of preparing research for publication and submission to a peer-reviewed medical journal, and a departmental award in recognition for the best resident scholarly project each year. Since the inception of this program, five classes have graduated a total of 16 residents. Ten residents submitted their research studies for peer review and published their scholarly projects in seven dermatology journals through the current academic year. These articles included three prospective investigations, three surveys, one article related to dermatology education, one retrospective chart review, one case series, and one article about dermatopathology. An additional article from a 2012 graduate about dermatology education has also been submitted to a journal. This new program for residents was adapted from our historically successful Dermatology Honors Research Program for medical students at The University of Texas Medical Branch. Our experience with this academic initiative to promote dermatology research by residents is outlined. It is recommended that additional residency programs should consider adopting similar research programs to enrich resident education.

Keywords: dermatology, resident, research, education, accreditation

\section{Introduction}

In 2001, the Department of Dermatology at The University of Texas Medical Branch (UTMB) began participating in UTMB's Honors Research Program. The Dermatology Honors Research Program is a voluntary, non-degree honors program in which participating medical students and their dermatology mentors submit a formal research proposal to the multidisciplinary institutional honors committee (MIHC). The MIHC reviews the proposal and suggests changes if needed. The proposal must have scientific merit, have the supporting departmental commitment for the resources needed to complete the study, and be designed for completion before the student's projected graduation date. Once approved, the student conducts the study under faculty supervision, analyzes collected data with a biostatistician, writes a thesis, and presents the research to the departmental ad hoc committee in a public PowerPoint Presentation. ${ }^{1}$ 
Twenty-four UTMB medical students have completed this program through 2011. This program for medical students was so successful, that in 2005 the departmental decision to adapt it for dermatology residents was made.

The Accreditation Council for Graduate Medical Education Common Program Requirements include resident scholarly activity. ${ }^{2}$ The program also requires that residency programs “... should allocate adequate educational resources to facilitate resident involvement in scholarly activities." 2 Prior to the creation of the scholarly project at UTMB, resident research activities were encouraged, but there was no organized departmental infrastructure to support and track such scholarly activity. This article will describe our scholarly project program requirement, curriculum, and goals for dermatology residents at UTMB. Dermatology applicants are informed about this program requirement at UTMB during their interview, and it is addressed in our Dermatology Resident Handbook, which is reviewed with all incoming dermatology residents in July each year.

\section{Methods}

Since 2005, eleven UTMB dermatology residents have participated in the scholarly project. The first group of residents completed their projects in 2008. Funding for study materials and financial support for a biostatistician consultant to participate in study design, statistical analysis, and writing the statistical portion of the results section has been through designated departmental professorship accounts.

\section{Description of required dermatology resident scholarly project}

All current UTMB dermatology residents are required to complete a basic science or clinical scholarly research project related to dermatology and submit it for peer-reviewed publication during their residency. Alternatively, the resident may select an educational curricular project, which may also be suitable for presentation and publication. A dermatology faculty mentor and a topic should be selected no later than January of the second postgraduate year of dermatology training. While the complexity and scope of these dermatology scholarly projects may vary according to the resident's interest and experience, it is anticipated that many of these studies will require institutional review board (human subjects) or institutional animal care and use committee (animal research) approval. Basic science and clinical research projects must be submitted for peer-reviewed journal publication by December 31 of the final year of the resident's dermatology training, although earlier completion and journal submission is encouraged. An optional 1- or 2-week research elective is available for fourth postgraduate year (PGY4) residents, to complete the written portion of the project. The resident should maintain a portfolio on their research project and include such documents as the institutional review board proposal and response, submitted abstracts and/or posters, presentation slides, and the submitted manuscript. A research presentation for all completed projects to the entire dermatology department is required by June of the PGY4 year. A written evaluation (Figure 1) by one of the dermatology faculty attending this presentation will be included in the resident's departmental folder.

\section{Program guidelines for I- or 2-week dermatology resident research elective}

1. Only PGY4 residents may participate.

2. The research must relate to the completion of the scholarly project (abstract, poster, PowerPoint, and/or manuscript as appropriate).

3. PGY4 residents taking this elective must submit a written proposal one month before the start date. The proposal should contain the name of the scholarly project, the name of the faculty mentor, a summary of progress on the project, and a detailed outline of the activities (goals and objectives) planned during the research elective (data analysis, reading, and writing). The faculty advisor, the chair and the program director must approve the research elective proposal and sign it. If the resident elects to take two 1-week research elective periods instead of one 2-week research elective, two separate proposals must be submitted with signatures.

4. The expectation for this research elective is the production of written work by the resident by the end of the research elective, for example a poster or abstract for submission to a meeting, or a draft manuscript. The written work must be in the proper format for submission and include references.

5. The resident must meet with their faculty mentor each week of the elective to discuss the project.

6. Participants in the research elective are required to report to their UTMB office each day during the research elective. Although every attempt will be made to provide protected time from clinics, an emergency may require clinic involvement. Residents on the research elective will be expected to continue to attend academic and educational departmental functions.

A written evaluation (Figure 2) by the faculty advisor, signed by the research resident, must be completed at the end of this elective and filed in the resident portfolio, with the completed work product. 
Date:

Resident presenting:

Faculty evaluating presentation:

1. Is the resident research presented logically and clearly?

2. Is the resident able to answer any questions asked about their research presented by other residents, students, and faculty?

3. What, if anything, could be done by the resident to improve the quality and effectiveness of their research presentation?

Resident signature

Faculty signature

Figure I Dermatology faculty evaluation of resident scholarly project presentation.

\section{Resident research award}

Each year the dermatology faculty vote to select a PGY4 dermatology resident for the Dermatology Resident Scholarly Research Project Award. Factors to be considered are the quality of the scholarly project, its publication in a peerreviewed journal, and any recognition awarded to the work (eg, by the Texas Dermatological Society, the American Academy of Dermatology, the National Student Research Forum, or the American Society for Dermatologic Surgery Young Investigators Writing Competition). Other factors considered by faculty are general research and scholarly activity during dermatology residency. The dermatology chair will present a certificate to the recipient at the annual graduation dinner, and the awarded resident's name will be added to the Resident Research Award Plaque in the dermatology conference room.

\section{Results}

Through the 2011-2012 academic year ten dermatology residents published their scholarly projects in peer-reviewed dermatology journals, and another submitted a paper for publication..$^{3-12}$ These residents produced three prospective investigations, three surveys, two educational methodology articles, one retrospective chart review, one case series, and one dermatopathology article.

Since the initiation of this educational program in 2005, five classes have completed training (2008 to 2012), with 16 dermatologists graduating. Initially, resident participation

Date:

Resident:

Research topic:

Faculty advisor:

Dates of this elective:

Please provide your evaluation of the research resident's progress in each of the three areas:

Data analysis:

Reading:

Writing:

Was a meeting abstract, poster, PowerPoint, or manuscript completed during this research elective?

Was a meeting abstract, poster, or manuscript submitted for a meeting program or for publication during this elective? If so, please provide the details of this submission.

Resident signature

Faculty signature

Figure 2 Supervising faculty evaluation for dermatology resident research elective. 
was voluntary and not required. However, nonparticipation by residents is no longer an option since the class that began residency in 2009, accounting for $100 \%$ resident participation in 2012 for the first time since the program began.

\section{Discussion}

Publications from multiple specialties have addressed the issue of research during residency training. ${ }^{13-16}$ Unlike many other specialties before the implementation of strict duty-hour regulations, ${ }^{17}$ dermatology has the advantage of residency programs structured to promote research activities. Dermatology enjoys an abundance of intellectual talent in the current cohort of dermatology residents. Implementing research activities to residency programs can be highly successful: after the introduction of a research training program in physical medicine and rehabilitation, numbers of publications statistically increased compared with prior program benchmarks. ${ }^{18}$

Engaging dermatology residents in substantive research projects was an incremental process at UTMB. When the scholarly project was first initiated, there was concern about making it a program requirement because of uncertainty about whether its goals could be achieved during residency training. For the first 2005-2008 resident group, the scholarly project was encouraged but not required. Initially, one former UTMB medical student who had completed the dermatology research honors program, and who continued at UTMB for his dermatology residency, was encouraged to prepare his student project for publication and to submit it. However, once the scholarly project was adopted as a program requirement the following year, research initiated as a medical student was no longer permitted to complete this program requirement. While the dermatology honors research program for medical students remains completely voluntary and does not currently require submission of a manuscript for peer review, the derivative scholarly project for residents differs because it is now a program requirement for all residents and requires submission of a manuscript for peer review. Residents enter our residency with knowledge about this requirement, and typically have more time to prepare a manuscript and submit it for publication over their 3 years of dermatology residency than medical students, who often are typically limited to 1.5 years of research activity before graduation and their first year of postgraduate education, often at another institution. In addition, these two programs have different professional aims: medical students are encouraged to engage in research, often for the first time, and may not obtain publishable results by the end of their endeavors. However, due to program design, medical students in this situation are still encouraged to present their thesis and with successful defense, are awarded graduation research honors.

Published scholarly projects have been in areas of historical program strengths and include dermatologic surgery, dermatopathology, dermatology education, and prison dermatology. Our residency program is continuing to grow in faculty and resident numbers, and with the addition of each new dermatology faculty, professional expertise expands and resident opportunities grow in more areas of dermatologic research. During our most recent site visit by the dermatology residency review committee site visitor, this research program for dermatology residents received several positive comments and a request that this information be disseminated to other dermatology residency programs. Although most of our residents enter private dermatology practices more than 100 miles from Galveston, ${ }^{19}$ the additional dimension in research training during dermatology residency adds to their depth of experience in the specialty. In addition, the adoption of the scholarly project requirement has resulted in a cultural shift within the department that is more supportive of and enthusiastic for dermatology research by the residents and faculty.

\section{Conclusion}

Residency programs may find adoption of a similarly structured research program beneficial to resident research productivity and publication.

\section{Disclosure}

The authors report no conflicts of interest in this work.

\section{References}

1. Wagner RF Jr, Lewis SA. Teaching medical students dermatology research skills: six years of experience with The University of Texas Medical Branch dermatology non-degree research honors program, 2001-2006. Dermatol Online J. 2006;12:20.

2. ACGME. Common Program Requirements. Available at: http://www. acgme.org/acgmeweb/Portals/0/dh_dutyhoursCommonPR07012007. pdf. Accessed April 9, 2013.

3. Ramirez M, Magee N, Diven D, et al. Topical imiquimod as an adjuvant to laser tattoo removal of mature tattoos in an animal model. Dermatol Surg. 2007;33:319-325.

4. Perri A, Chan C, Uchida T, Wagner RF Jr. Patients' recall of visible skin biopsy sites. Skin Cancer. 2008;23:61-67.

5. Dimmick J, Laster JS, Warren DB, Wagner RF. UV lip protection in a high risk population. HPC Supplement Focus on Sun Care. 2009;3:14-15. Available at http://hpc-today.teknoscienze.com/testata.asp?id_testata=17 9\&folder=supplements\&id_articolo=2435. Accessed April 9, 2013.

6. Matherne R, Marek M, Uchida T, Wagner RF Jr. Predictors of patient wound repair satisfaction following Mohs surgery for nonmelanoma skin cancers. Skin Cancer. 2010;25:7-10.

7. Petitt M, Allison A, Shimoni T, Uchida T, Raimer S, Kelly B. Lymphatic invasion detected by D2-40/S-100 dual immunohistochemistry does not predict sentinel lymph node status in melanoma. J Am Acad Dermatol. 2009;61:819-828. 
8. Stephens J, Raimer SS, Wagner RF Jr. The dermatology acting internship. Dermatol Online J. 2011;17:9.

9. Raimer D, Group AR, Petitt MS, et al. Porcine xenograft biosynthetic wound dressings for the management of postoperative Mohs wounds. Dermatol Online J. 2011;17:1

10. Coury C, Kelly BC. Prison dermatology: experience in the Texas Department of Criminal Justice dermatology clinic. J Correct Health Care. 2012;18:302-308.

11. Nosrati N, Hunter L, Kelly E. Efficacy of Nd:YAG Laser for the treatment of hidradenitis suppurativa. JCDSA. 2012;2:83-87.

12. Group A, Philips R, Kelly E. Cosmetic dermatology training in residency: results of a survey from the residents' perspective. Dermatol Surg. 2012;38:1975-1980.

13. Kanna B, Deng C, Erickson SN, Valerio JA, Dimitrov V, Soni A. The research rotation: competency-based structured and novel approach to research training of internal medicine residents. BMC Med Educ. 2006;6:52

14. Boninger ML, Chan L, Harvey R, et al. Resident research education in physical medicine and rehabilitation: a practical approach. Am J Phys Med Rehabil. 2001;80:706-712.
15. Segal LS, Black KP, Schwentker EP, Pellegrini VD. An elective research year in orthopaedic residency: how does one measure its outcome and define its success? Clin Orthop Relat Res. 2006;449:89-94.

16. Vinci RJ, Bauchner H, Finkelstein J, Newby PK, Muret-Wagstaff S, Lovejoy FH Jr. Research during pediatric residency training: outcome of a senior resident block rotation. Pediatrics. 2009;124:1126-1134.

17. Oxnard GR, Zinkus TM, Bazari H, Wolf M. Integrating research training into residency: tools of human investigation. Acad Med. 2009;84:1295-1300

18. Millis SR, Campagnolo DI, Kirschblum S, Elovic E, Jain SS, DeLisa JA. Improving resident research in physical medicine and rehabilitation: impact of a structured training program. J Spinal Cord Med. 2004;27:428-433.

19. Resneck JS Jr, Kostecki J. An analysis of dermatologist migration patterns after residency training. Arch Dermatol. 2011;147:1065-1070.
Advances in Medical Education and Practice

\section{Publish your work in this journal}

Advances in Medical Education and Practice is an international, peerreviewed, open access journal that aims to present and publish research on Medical Education covering medical, dental, nursing and allied healthcare professional education. The journal covers undergraduate education, postgraduate training and continuing medical education

\section{Dovepress}

including emerging trends and innovative models linking education, research, and healthcare services. The manuscript management system is completely online and includes a very quick and fair peer-review system. Visit http://www.dovepress.com/testimonials.php to read real quotes from published authors.

Submit your manuscript here: http://www.dovepress.com/advances-in-medical-education-and-practice-journal 